\title{
Colipase Enhances Hydrolysis of Dietary Triglycerides in the Absence of Bile Salts
}

\author{
Lars Bläckberg, Olle Hernell, Gunilla Bengtsson, and \\ Thomas Olivecrona, Department of Physiological Chemistry and \\ Department of Pediatrics, University of Umeå, S-901 87 Umeå, Sweden
}

A B S T R A C T This study explores how dietary lipids are digested when intraduodenal bile salts are low or absent. Long-chain triglycerides emulsified with phosphatidylcholine were found to be hydrolyzed very slowly by pancreatic lipase alone, as if the surface layer of phospholipids enveloping the triglycerides impeded the action of the enzyme. Colipase enhanced triglyceride hydrolysis severalfold, both when added before or after the lipase. Hydrolysis became even more rapid when the emulsion was first incubated with pancreatic phospholipase. Hydrolysis of long-chain triglycerides was also severely impeded when other proteins were added to the system, probably because they adsorbed to the oil-water interface of the emulsion droplets. It was previously known that bile salts can relieve such inhibition, presumably by desorbing the adsorbed proteins. Colipase was found to enhance hydrolysis severalfold in a dose-dependent manner even in the absence of bile salts, i.e., it could partially or completely relieve the inhibition depending upon the amount and the type of inhibitory protein added to the system. Prior exposure of a protein-coated triglyceride emulsion to another lipase also enhanced the rate at which pancreatic lipase could then hydrolyze the lipids.

Most dietary triglycerides are probably presented for intestinal digestion in emulsions covered by proteins and/or phospholipids. These emulsions would be hydrolyzed slowly by pancreatic lipase alone. However, through the action of the lipase in stomach contents and of pancreatic phospholipase and through the lipolysis-promoting effects of colipase, these triglycerides can be rather efficiently hydrolyzed, even in the absence of bile salts.

\section{INTRODUCTION}

The physiological function of pancreatic lipase together with its protein cofactor, colipase, is to

Received for publication 16 April 1979 and in revised form 27 June 1979. hydrolyze dietary lipids (1). The mechanism of lipolysis and the effects of colipase have been thoroughly investigated in monolayer systems (2-6) and with emulsions of short-chain triglycerides (7-9). These studies have demonstrated that lipase must adsorb to the lipid-water interface of its insoluble substrate (10). However, in the presence of bile salts at physiological concentrations, this binding does not take place unless colipase is also present $(4,8,9)$. Thus, the role of colipase in these systems seems to be to bind to the lipid-water interface and provide an anchor for the binding of lipase. More recently it has been suggested that in the intestine lipase and colipase may associate with the bile lipoprotein complex and that this association may be the functional lipolytic entity that adsorbs to the triglyceride droplets (11). Much less attention has been paid to the action of the lipase on emulsions similar to its physiological substrate, i.e., long-chain triglycerides enveloped by a surface layer of proteins and/or polar lipids. Milk fat droplets are an example of such a physiological fat emulsion; but, interestingly enough, they appear to be a poor substrate for pancreatic lipase (12). Data in this paper show that triglyceride droplets enveloped by a layer of phospholipids are hydrolyzed very slowly by the lipase. Brockerhoff (13) demonstrated that albumin inhibits lipolysis and proposed that the inhibition occurred through adsorption of albumin to the interface, which denies lipase access to the triglycerides. By using tributyrin, Borgström and Erlanson (14) have shown that the inhibition can be relieved by bile salts, presumably because they desorb some adsorbed proteins from the triglyceride droplets (15). These observations suggest that in the intestine bile salts might be necessary to clear lipid droplets of adsorbed proteins so that pancreatic lipase can hydrolyze the triglycerides. However, in humans with bile fistula, intraduodenal lipolysis seems to be relatively unimpaired (16). Infants ingest large quantities of milk lipids, which are present in phospholipid-protein-stabilized droplets (17). In many cases 
their bile salt concentrations are low (18), but they digest the milk lipids rather efficiently (19). These observations pose a question: how can pancreatic lipase digest dietary lipids such as those in milk fat globules when there is little or no bile salt present? We report here that under these conditions colipase itself enhances lipase action manyfold.

\section{METHODS}

Bovine serum albumin, lysozyme, porcine pancreatic phospholipase $A_{2}, \beta$-lactoglobulin, and gum arabic were from Sigma Chemical Co. (St. Louis, Mo.). Lactoferrin was purified from human milk. ${ }^{1}$ Intralipid $10 \%$ (Cutler Laboratories, Inc., Berkeley, Calif.) that contained $\left[{ }^{14} \mathrm{C}\right]$ oleic acid-labeled triolein was a kind gift from AB Vitrum (Stockholm, Sweden). It is an emulsion of soy bean triglycerides in egg yolk phosphatidylcholine manufactured for parenteral nutrition (20). Sodium taurocholate and triolein labeled with $\left[{ }^{3} \mathrm{H}\right]$ oleic acid were kindly prepared by Dr. L. Krabisch (Lund, Sweden). The triolein was purified by thin-layer chromatography before use. Long-chain triglycerides to be used in the gum arabic emulsion were purified from olive oil (21). Lipase and colipase were purified from pig pancreas according to Verger et al. (22) and Erlanson and Borgström (23). In the purification of lipase, the CM-cellulose step, which separates two forms of the lipase (A and B), was omitted. The colipase preparation was a mixture of colipase 1 and 2. Lipase from Pseudomonas fuorescens (24) was a kind gift from Amano Pharmaceutical Co. (Nagoya, Japan).

To prepare the triglyceride-gum arabic emulsion, $80-\mathrm{mg}$ triglycerides from olive oil were mixed with a trace amount of $\left[{ }^{3} \mathrm{H}\right]$ oleic acid-labeled triolein $\left(4 \times 10^{7} \mathrm{cpm}\right)$ in heptane and the solvent was evaporated under nitrogen. $1 \mathrm{ml}$ of $10 \%$ gum arabic and $3 \mathrm{ml}$ of $0.05 \mathrm{M}$ Tris- $\mathrm{HCl}$ buffer $(\mathrm{pH} 7.5)$ was then added, and the mixture was sonicated in ice-water for $4 \mathrm{~min}$ with a Branson Sonifier A-30 (Branson Ultrasonics Corp., Danbury, Conn.). Before it was used as substrate, the labeled Intralipid was separated by centrifugation as follows: $100 \mathrm{mg}$ / $\mathrm{ml}$ of sucrose was added, and the emulsion was layered under an approximately equal volume of $0.05 \mathrm{M}$ Tris- $\mathrm{HCl}$ buffer (pH 7.5). The tubes were centrifuged at $25,000 \mathrm{rpm}$ for $30 \mathrm{~min}$ at $4^{\circ} \mathrm{C}$ in a Beckman L-2 ultracentrifuge with an SW 50:1 rotor (Beckman Instruments, Inc., Spinco Div., Palo Alto, Calif.). The tubes were sliced, and the top phases were resuspended. This was done to remove the phospholipids not attached to the triglyceride-rich droplets. The incubations were carried out in a water bath shaking at 50 strokes/min. Fatty acids were extracted, and their radioactivity was determined as described by Belfrage and Vaughan (25).

\section{RESULTS}

Hydrolysis of a phospholipid-coated emulsion. When pancreatic lipase was added to a medium that contained Intralipid, hydrolysis of the triglycerides was initially very slow (Fig. 1a), but the rate increased somewhat with time. Such lag-phases have previously been observed with pancreatic lipase both in monolayer systems $(5,6)$ and with tributyrin emulsions (9). In this series of experiments the lag-phase was more marked with Intralipid as the substrate than with the gum arabic

\footnotetext{
${ }^{1}$ Bläckberg, L., and O. Hernell. Manuscript in preparation.
}

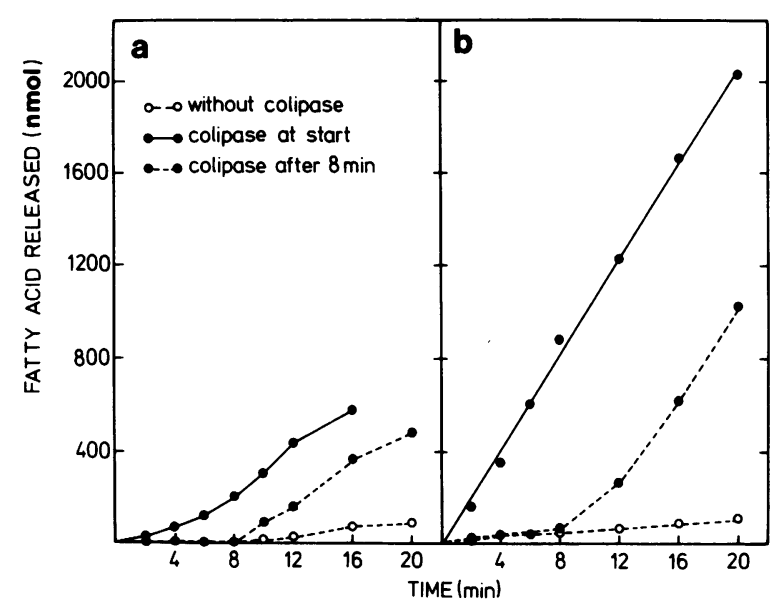

FIGURE 1 Effect of colipase on hydrolysis of triglycerides by pancreatic lipase. (a) Conditions were as in Table I, with triglyceride-rich particles from Intralipid as the substrate. (b) Conditions were as in Table II, with the triglyceride-gum arabic emulsion and $5 \mathrm{mg} / \mathrm{ml}$ bovine serum albumin. Colipase $(10 \mu \mathrm{g} / \mathrm{ml})$ was added either immediately before the lipase $(0.2 \mu \mathrm{g} / \mathrm{ml})$ or $8 \mathrm{~min}$ after the lipase.

emulsion (compare Fig. la and b). With Intralipid the lag-phase was shortened by the addition of phospholipase and/or bile salts. Thus, the longest lag-phases encountered were those shown in Fig. 1a. The slow rate of triglyceride hydrolysis was not unique to Intralipid; triolein emulsified in rat liver phosphatidylcholine was also hydrolyzed very slowly (data not shown). The phospholipids not associated with the emulsion droplets had been removed by centrifugation. Thus, the inhibition must have been a result of the phospholipids enveloping the triglycerides. If colipase were also present, hydrolysis started earlier and the rate became severalfold higher (Fig. la). When the reaction was initiated with lipase alone, and colipase was then added, the rate rapidly increased and became similar to that seen when colipase was added before the lipase. Thus, the slow rate of hydrolysis in the absence of colipase was not a result of inactivation of the enzyme (13). The effect of colipase was rapid; the rate of hydrolysis increased immediately when colipase was added $8 \mathrm{~min}$ after the lipase (Fig. la). Thus, whatever the lag-phase signifies, it depends mainly upon a slow process related to the enzyme, e.g., its adsorption to the emulsion $(5,9)$.

Table I illustrates the effects of pancreatic phospholipase and/or bile salt on the rate at which the Intralipid triglycerides were hydrolyzed in the presence or absence of colipase. During the first parts of the incubations, the rate of hydrolysis increased with time, in some cases well beyond 5 min (cf., Fig. la). At later stages the rate often declined again (cf., Fig la). Consequently, the relation between the rates under different conditions changed with time. However, qualita- 
TABLE I

Effect of Phospholipase $A_{2}$ and/or Śdium Taurocholate on Hydrolysis of Intralipid Triglycerides by Pancreatic

Lipase in the Presence or Absence of Colipase

\begin{tabular}{cccc}
\hline Colipase & Phospholipase $A_{2}$ & Sodium taurocholate & Fatty acids released \\
\hline & & & $n$ nol \\
- & - & - & 12 \\
+ & - & - & 890 \\
- & - & + & 14 \\
+ & - & + & 630 \\
- & + & - & 220 \\
+ & + & - & 2,750 \\
- & + & + & 1,730 \\
+ & + & + & 5,340 \\
\hline
\end{tabular}

0.1 M Tris- $\mathrm{HCl}(\mathrm{pH} 7.5), 4 \mathrm{mM} \mathrm{Ca}{ }^{++}$, triglyceride-rich particles from Intralipid corresponding to $4 \mathrm{mg} / \mathrm{ml}$ triglycerides, $37^{\circ} \mathrm{C}$. The final volume was $1 \mathrm{ml}$. The system, with or without $10 \mathrm{mM}$ sodium taurocholate, was incubated $10 \mathrm{~min}$ before lipase $(1 \mu \mathrm{g} / \mathrm{ml}$ ) was added. As indicated, $2 \mu \mathrm{g} / \mathrm{ml}$ phospholipase was added $2 \mathrm{~min}$ before the lipase and/or 10 $\mu \mathrm{g} / \mathrm{ml}$ colipase was added immediately before the lipase. The data listed are the amounts of fatty acids released during the first $8 \mathrm{~min}$ of incubation per milliliter of medium.

tively the same differences were found, whether the maximal rates were compared, or, as in Table $I$, the amounts of fatty acids released during the first $8 \mathrm{~min}$ of incubation were compared. Preincubation of the emulsion with pancreatic phospholipase caused a severalfold increase in the rate at which pancreatic lipase hydrolyzed the triglycerides. Sodium taurocholate increased the lipase activity only when phospolipase was also present. In this case a high rate of hydrolysis was obtained even when no colipase was added. However, the highest rate of hydrolysis was observed with a system that contained phospholipase, taurocholate, and colipase. When the amount of colipase was increased fivefold compared with that in Table I, the lipase activity only increased $\cong 20 \%$ (in the absence of phospholipase and taurocholate). Thus, it seems unlikely that colipase alone could give as high rates of hydrolysis as in the complete system with phospholipase and bile salts.

Hydrolysis of a protein-coated emulsion. When no other proteins were added, pancreatic lipase rapidly hydrolyzed the triglycerides in a gum arabic emulsion, and colipase had only a small effect (Table II). Preincubation of the gum arabic emulsion with other proteins before the lipase was added caused a decrease in the rate of hydrolysis. The type and amount of protein added (Table II), as well as the time of preincubation, influenced the degree of inhibition. It is likely that the inhibition was caused by adsorption of the proteins to the emulsion. This hypothesis is supported by the fact that the inhibition persisted after the emul-
TABLE II

Effect of Colipase on the Inhibition of Pancreatic Lipase Activity Caused by some Proteins

\begin{tabular}{|c|c|c|}
\hline \multirow[b]{2}{*}{ Protein } & \multicolumn{2}{|c|}{ Fatty acids released } \\
\hline & Without colipase & With colipase \\
\hline & \multicolumn{2}{|c|}{ nmol } \\
\hline - & 1,540 & 1,890 \\
\hline Lactoferrin & 660 & 2,450 \\
\hline Lysozyme & 110 & 1,570 \\
\hline Bovine serum albumin & 60 & 2,290 \\
\hline$\beta$-Lactoglobulin & 30 & 780 \\
\hline
\end{tabular}

$0.1 \mathrm{M}$ Tris- $\mathrm{HCl}$ (pH 7.5), $4 \mathrm{mM} \mathrm{Ca}^{++}$, triglyceride-gum arabic emulsion corresponding to $4 \mathrm{mg} / \mathrm{ml}$ triglyceride, $37^{\circ} \mathrm{C}$. The final volume was $1 \mathrm{ml}$. The various proteins were added to final concentrations of $5 \mathrm{mg} / \mathrm{ml} 20 \mathrm{~min}$ before the lipase $(0.4$ $\mu \mathrm{g} / \mathrm{ml})$. When colipase $(10 \mu \mathrm{g} / \mathrm{ml})$ was included, it was added immediately before the lipase. The data listed are the amounts of fatty acids released during the first $8 \mathrm{~min}$ of incubation per milliliter of medium.

sion had been isolated by centrifugation (cf. Fig. 3). The inhibition was to a varying extent relieved when colipase $(10 \mu \mathrm{g} / \mathrm{ml})$ was added (Table II). Colipase also increased the rate of hydrolysis when it was added $8 \mathrm{~min}$ after the lipase (Fig. lb). In the systems with lactoferrin or bovine serum albumin, the rate of hydrolysis with colipase was in fact higher than when no proteins were added. In the presence of $0.5 \mathrm{mg} / \mathrm{ml}$ of $\beta$ lactoglobulin the lipase activity increased dramatically with the amount of colipase added. At the three highest concentrations of colipase the maximal effect was probably achieved because there was no increase in the rate of hydrolysis on further addition of colipase (Fig. 2). This rate was similar to that obtained without any proteins added (compare Fig. 2 and Table II) and was more than 10 -fold higher than the rate with this amount of $\beta$-lactoglobulin but no colipase. In the presence of $5 \mathrm{mg} / \mathrm{ml}$ of $\beta$-lactoglobulin, however, even the largest amount of colipase $(50 \mu \mathrm{g} / \mathrm{ml})$ was not enough to relieve the inhibition (Fig. 2).

In contrast to pancreatic lipase the lipase from $P$. fluorescens hydrolyzed a protein-coated triglyceridegum arabic emulsion (Fig. 3). When pancreatic lipase was added $4 \mathrm{~min}$ after the bacterial lipase, the rate of hydrolysis increased and became higher than the sum of the rates for each lipase alone. Thus, partial hydrolysis made the emulsion more readily hydrolyzed by pancreatic lipase, even in the absence of colipase.

\section{DISCUSSION}

The experiments with Intralipid showed that when long-chain triglycerides are presented to pancreatic lipase in droplets enveloped by phospholipids (20), 


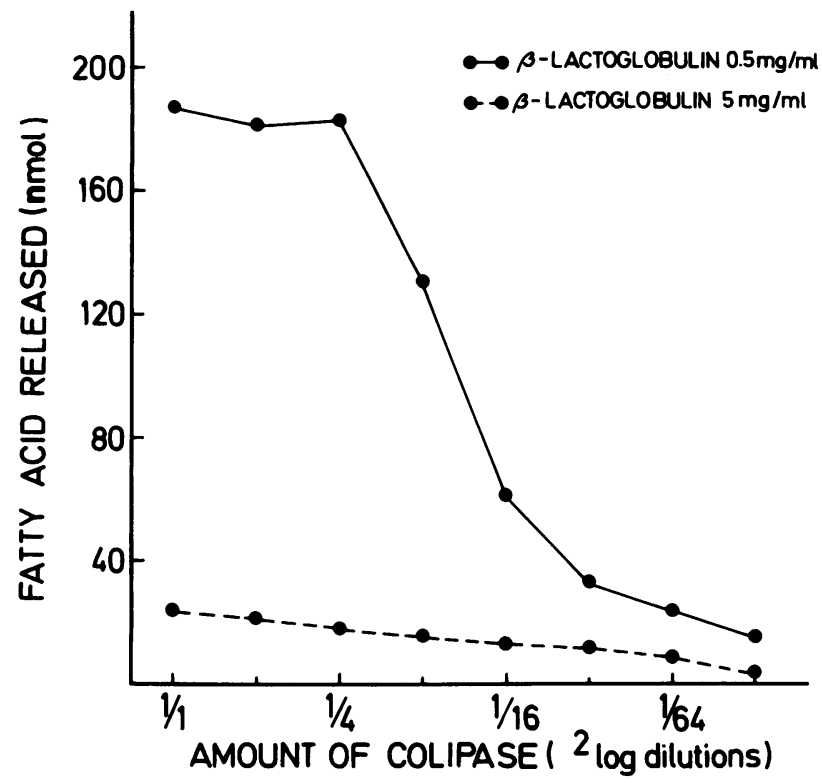

FIGURE 2 Effect of colipase on triglyceride hydrolysis by pancreatic lipase in the presence of two different amounts of $\beta$-lactoglobulin. Conditions are as in Table II, but the amount of colipase was varied from $50 \mu \mathrm{g} / \mathrm{ml}(1 / 1)$ to 0.39 $\mu \mathrm{g} / \mathrm{ml}(1 / 128) .0 .5$ or $5 \mathrm{mg} / \mathrm{ml} \beta$-lactoglobulin was added $20 \mathrm{~min}$ before the lipase $(0.2 \mu \mathrm{g} / \mathrm{ml})$. The incubations were for $2 \mathrm{~min}$.

they are hydrolyzed very slowly. Two mechanisms were demonstrated by which the inhibition could be reduced. Addition of colipase before or several minutes after the lipase increased the activity severalfold. Preincubation with phospholipase also enhanced triglyceride hydrolysis, and when colipase was present high activity was obtained. Apparently, lysophosphatidylcholine caused less inhibition than phosphatidylcholine. Bile salts further enhanced hydrolysis, probably by desorbing some of the lysophospholipids from the interface (15). Although colipase by itself enhanced hydrolysis, and phospholipase with or without bile salts also enhanced hydrolysis, optimal activity seemed to require both colipase and degradation-removal of the phospholipids. With the complete system there was no discernable lagphase and rate of hydrolysis was similar to that observed with the triglyceride-gum arabic emulsion (compare Tables I and II), which suggests that it may be close to the "uninhibited" rate for hydrolysis of emulsified long-chain triglycerides.

It was previously known that some proteins inhibit the action of pancreatic lipase on emulsified triglycerides $(13,14,26)$, and this is confirmed in our work. Others have shown that this type of inhibition can be relieved by bile salts $(14,26)$. Our study demonstrates that this inhibition can also be relieved by colipase. For instance, in the experiments with albumin in Table II, colipase increased the rate of hydrolysis more than 35 -fold. A

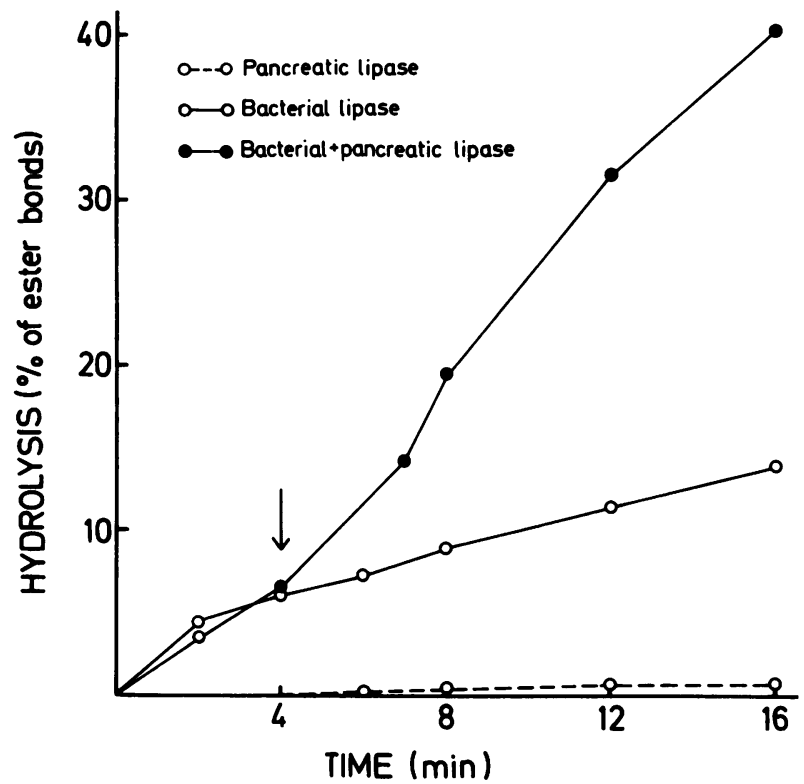

Figure 3 Effect of partial hydrolysis by another lipase on the activity of pancreatic lipase against a protein-coated triglyceride emulsion. Assay medium with the composition described in the legend to Table II was incubated with 10 $\mathrm{mg} / \mathrm{ml}$ of albumin for $20 \mathrm{~min}$ at $37^{\circ} \mathrm{C}$. The medium was then separated by centrifugation as described for Intralipid in Methods. In this way, protein not attached to the emulsion droplets was removed. After centrifugation, the top layer was resuspended and used to prepare a second set of assay mixtures with the same final composition as in Table II, which were then incubated at $37^{\circ} \mathrm{C}$ with $1 \mu \mathrm{g} / \mathrm{ml}$ pancreatic lipase ( $0.2 \mu \mathrm{g} / \mathrm{ml}$ lipase from $P$. fluorescens with $1 \mu \mathrm{g} / \mathrm{ml}$ of pancreatic lipase added $4 \mathrm{~min}$ after the bacterial lipase as indicated by the arrow (O).

similar effect, but less marked, can be seen in Fig. 1 in the paper by Borgström and Erlanson (14). However, colipase alone could not fully relieve the inhibition under all circumstances, as exemplified by the experiment with a large amount of $\beta$-lactoglobulin (Fig. 2). Studies in model systems have demonstrated that colipase can stabilize lipase against surface denaturation $(6,13)$ and enhance its binding to lipid emulsions $(6,8,9)$. In our system its effect was not primarily to stabilize the lipase. Whether the effect was mediated on the binding of lipase to the emulsion can not be deduced from our data. It is of interest, however, to note that this effect both with the phospholipid-covered and the protein-covered emulsions was similar to the effects of apolipoprotein CII on lipoprotein lipase in these systems. In that case, the main effect is not on binding, but apolipoprotein CII somehow makes the enzyme at the interface more productive in hydrolysis. ${ }^{2}$

\footnotetext{
${ }^{2}$ Bengtsson, G., and T. Olivecrona. Manuscript in preparation.
} 
With the emulsions studied here, colipase enhances the activity of pancreatic lipase but not that of lipoprotein lipase, and, conversely, apolipoprotein CII only enhances the activity of lipoprotein lipase (unpublished observation; cf., [6, 27]). This suggests specific recognition between the enzymes and their respective cofactors. There is ample evidence for such interaction between pancreatic lipase and colipase $(28,29)$. Evidence has been presented that pancreatic lipase undergoes "surface activation," presumably a conformational change which makes it catalytically more efficient (30). Because the lipase-colipase complex is at least as active as lipase alone at model interfaces, it follows that colipase binding must be compatible with the surface-activated conformation and more likely stabilizes it. In our systems, lipase may not attain its most active conformation/orientation at the interface unless colipase is present.

Another mechanism by which the inhibition by proteins could be decreased was by hydrolysis itself. The surface-active products of lipolysis locate at the oilwater interface of the triglyceride droplets and probably desorb some of the inhibitory proteins. This has been directly demonstrated in experiments with lipoprotein lipase. ${ }^{2}$ In vivo, some hydrolysis of dietary triglycerides takes place in the stomach $(31,32)$. This has previously been demonstrated to facilitate digestion of milk fat globules by pancreatic lipase in the presence of bile salts and colipase $(33,34)$. These data suggest that the same is also true in the absence of bile salts and colipase. In fact, the main importance of gastric lipolysis may be under conditions when bile salts are either present in low concentrations or are absent altogether. We chose to use the bacterial lipase for these experiments because it was available in pure form, whereas the gastric or lingual lipase has not yet been purified.

These in vitro experiments were designed to explore how fat digestion takes place in the absence of bile salts. The conditions were not in all respects representative of those in vivo but are a simplified model. Thus, the effects of proteases were not tested, and model fat emulsions were used rather than food materials. Porcine lipase and colipase were used; as far as is known, their properties are similar to their human counterparts $(35,36)$. The highest concentration of colipase used (50 $\mu \mathrm{g} / \mathrm{ml}$, Fig. 2) corresponds with that in human intestinal contents; in all other cases the concentrations of lipase and colipase were less than those encountered in healthy adults (37). On the other hand, lipase concentrations similar to or even lower than those used in our in vitro studies are encountered in human infants during test meals (38). Thus, the situation in vivo is much more complex and variable than in our in vitro studies. With this reservation we propose the following picture of fat digestion when bile salts are low or absent. The first step is partial digestion of triglycerides in the stomach. In the intestine the phospholipids are hydrolyzed by pancreatic phospholipase. The lysophospholipids, fatty acids, and partial glycerides formed will help emulsify undispersed lipids (31) and will impede adsorption of proteins to the droplets. With proteinphospholipid covered lipid emulsions such as milk fat globules, egg yolk lipoproteins, etc., they may cause some desorption of protein. These two processes, i.e., degradation of phospholipids and desorption of protein will facilitate further hydrolysis of the triglycerides by pancreatic lipase. In addition, and perhaps more important, colipase enhances the action of the lipase manyfold even if some proteins and/or phospholipids remain on the lipid droplets.

\section{ACKNOWLEDGMENTS}

We thank Miss Kerstin Wiklund for her skillful technical assistance and Mrs. Karin Gladh for preparing the manuscript.

This work was supported by the Swedish Medical Research Council (13X-00727), The Swedish Baby Food Industry Fund for Nutritional Research, The Swedish Nutrition Foundation, The Wennergrenska Samfundet, The Swedish Society of Medical Sciences, and the Medical Faculty, University of Umeå.

\section{REFERENCES}

1. Brockerhoff, H., and R. G. Jensen. 1974. Lipolytic enzymes. Academic Press, Inc., New York. 34-90.

2. Garner, C. W., and L. C. Smith. 1970. Hydrolysis of monomolecular films of trioctanoin by porcine pancreatic lipase. Biochem. Biophys. Res. Commun. 39: 672-682.

3. Brockman, H. L., F. J. Kézdy, and J. H. Law. 1975. Isobaric titration of reacting monolayers: kinetics of hydrolysis of glycerides by pancreatic lipase B. J. Lipid Res. 16: 67-74.

4. Momsen, W. E., and H. L. Brockman. 1976. Effects of colipase and taurodeoxycholate on the catalytic and physical properties of pancreatic lipase $B$ at an oil-water interface. J. Biol. Chem. 251: 378-383.

5. Rietsch, J., F. Pattus, P. Desnuelle, and R. Verger. 1977. Further studies on the mode of action of lipolytic enzymes. J. Biol. Chem. 252: 4313-4318.

6. Verger, R., J. Rietsch, and P. Desnuelle. 1977. Effects of colipase on hydrolysis of monomolecular films by lipase. J. Biol. Chem. 252: 4319-4325.

7. Borgström, B., and C. Erlanson. 1973. Pancreatic lipase and colipase. Interactions and effects of bile salts and other detergents. Eur. J. Biochem. 37: 60-68.

8. Vandermeers, A., M. C. Vandermeers-Piret, J. Rathé, and J. Christophe. 1975. Effect of colipase on adsorbtion and activity of rat pancreatic lipase on emulsified tributyrin in the presence of bile salts. FEBS (Fed. Eur. Biochem. Soc.) Lett. 49: 334-337.

9. Borgström, B. 1977. The action of bile salts and other detergents on pancreatic lipase and the interaction with colipase. Biochim. Biophys. Acta. 488: 381-391.

10. Verger, R., and G. H. deHaas. 1976. Interfacial enzyme kinetics of lipolysis. Annu. Rev. Biophys. Bioeng. 5: 77117.

11. Lairon, D., G. Nalbone, H. LaFont, J. Leonardi, N. Domingo, J-C. Hauton, and R. Verger. 1978. Possible roles of bile lipids and colipase in lipase adsorption. Biochemistry. 17: 5263-5269. 
12. Cohen, M., R. G. H. Morgan, and A. F. Hofmann. 1971. Lipolytic activity of human gastric and duodenal juice against medium and long chain triglycerides. Gastroenterology. 60: 1-15.

13. Brockerhoff, H. 1971. On the function of bile salts and proteins as cofactors of lipase. J. Biol. Chem. 246: 58285831.

14. Borgström, B., and C. Erlanson. 1978. Interactions of serum albumin and other proteins with porcine pancreatic lipase. Gastroenterology. 75: 382-386.

15. Helenius, A., and K. Simmons. 1975. Solubilization of membranes by detergents. Biochim. Biophys. Acta. 415: 29-79.

16. Porter, H. P., D. R. Saunders, G. Tytgat, O. Brunser, and C. E. Rubin. 1971. Fat absorbtion in bile fistula man. Gastroenterology. 60: 1008-1019.

17. Patton, S., and T. W. Keenan, 1975. The milk fat globule membrane. Biochim. Biophys. Acta. 415: 273-309.

18. Murphy, G. M., and E. Signer, 1974. Bile acid metabolism in infants and children. Gut. 15: 151-163.

19. Hanna, F. M., D. A. Navarette, and F. A. Hsu. 1970. Calcium-fatty acid absorption in term infants fed human milk and prepared formulas simulating human milk. Pediatrics. 45: 216-224.

20. Carlson, L. A. 1979. Studies on the fat emulsion Intralipid ${ }^{R}$. I. Association of serum proteins to Intralipid triglyceride particles (ITP). Scand. J. Clin. Lab. Invest. In press.

21. Sémériva, M., and C. Dufour. 1972. Further studies on the exocellular lipase of Rhizopus Arrhizus. Biochim. Biophys. Acta. 260: 393-400.

22. Verger, R., G. H. deHaas, L. Sarda, and P. Desnuelle. 1969. Purification from porcine pancreas of two molecular species with lipase activity. Biochim. Biophys. Acta. 188: 272-282.

23. Erlanson, C., and B. Borgström. 1972. Purification and further characterization of co-lipase from porcine pancreas. Biochim. Biophys. Acta. 271: 400-412.

24. Sugiura, M., T. Oikawa, K. Kirano, and T. Inukai. 1977. Purification, crystallization and properties of triacylglycerol lipase from Pseudomonas fluorescens. Biochim. Biophys. Acta. 488: 353-358.

25. Belfrage, P., and M. Vaughan. 1969. Simple liquid-liquid partition system for isolation of labeled oleic acid from mixtures with glycerides. J. Lipid Res. 10: 341-344.

26. Fraser, G. P., and A. D. Nicol. 1966. Studies on human pancreatic lipase. Clin. Chim. Acta. 13: 552-562.

27. Ekman, R., and P. Nilsson-Ehle. 1975. Effects of apo- lipoproteins on lipoprotein lipase activity of human adipose tissue. Clin. Chim. Acta. 63: 29-35.

28. Patton, J. S., and P. A. Albertsson, C. Erlanson, and B. Borgström. 1978. Binding of porcine pancreatic lipase and colipase in the absence of substrate studied by two phase partition and affinity chromatography. J. Biol. Chem. 253: 4195-4202.

29. Patton, J. S., J. Donnér, and B. Borgström. 1978. Lipasecolipase interactions during gel filtration. High and low affinity binding situations. Biochim. Biophys. Acta. 529: 67-78.

30. Chapus, C., M. Sémériva, C. Borier-Lapierre, and P. Desnuelle. 1976. Mechanism of pancreatic lipase action. I. Interfacial activation of pancreatic lipase. Biochemistry. 15: 4980-4987.

31. Hamosh, M., H. L. Klaeveman, R. O. Wolf, and R. O. Scow. 1975. Pharyngeal lipase and digestion of dietary triglycerides in man. J. Clin. Invest. 55: 908-913.

32. Olivecrona, T., $\AA$. Billström, B. Fredrikzon, O. Johnson, and G. Samuelson. 1973. Gastric lipolysis of human milk lipids in infants with pyloric stenosis. Acta Paediatr. Scand. 62: 520-522.

33. Olivecrona, T., O. Hernell, T. Egelrud, A. Billström, H. F. Helander, G. Samuelson, and B. Fredrikzon. 1973. Studies on the gastric lipolysis of milk lipids in suckling rats and in human infants. In Dietary Lipids and Postnatal Development. C. Galli, G. Jacini, and A. Pecile, editors. Raven Press, New York. 77-89.

34. Edwards-Webb, J. D., and S. Y. Thompson. 1977. Studies on lipid digestion in the preruminant calf. 2. A comparison of the products of lipolysis of milk fat by salivary and pancreatic lipases in vitro. Br. J. Nutr. 37: 431-440.

35. Erlanson, C., and B. Borgström. 1970. Carboxyl ester hydrolase and lipase of human pancreatic juice and intestinal content. Behaviour in gel filtration. Scand. J. Gastroenterol. 5: 395-400.

36. Vandermeers, A., M. C. Vandermeers-Piret, J. Rathé, and J. C. Christophe. 1974. On human pancreatic triacylglycerol lipase: isolation and some properties. Biochim. Biophys. Acta. 370: 257-268.

37. Borgström, B., and H. Hildebrand. 1975. Lipase and colipase activities of human small intestinal contents after a liquid test meal. Scand. J. Gastroenterol. 10: 585-591.

38. Fredrikzon, B., and T. Olivecrona. 1978. Decrease of lipase and esterase activities in intestinal contents of newborn infants during test meals. Pediatr. Res. 12: 631-634. 